\title{
Clinics in diagnostic imaging (210)
}

Michael John $\underline{\text { Clarke }}^{1}$, MBBS, FRANZCR, Syed Zama Ali ${ }^{1}$, MBBS, FRCR

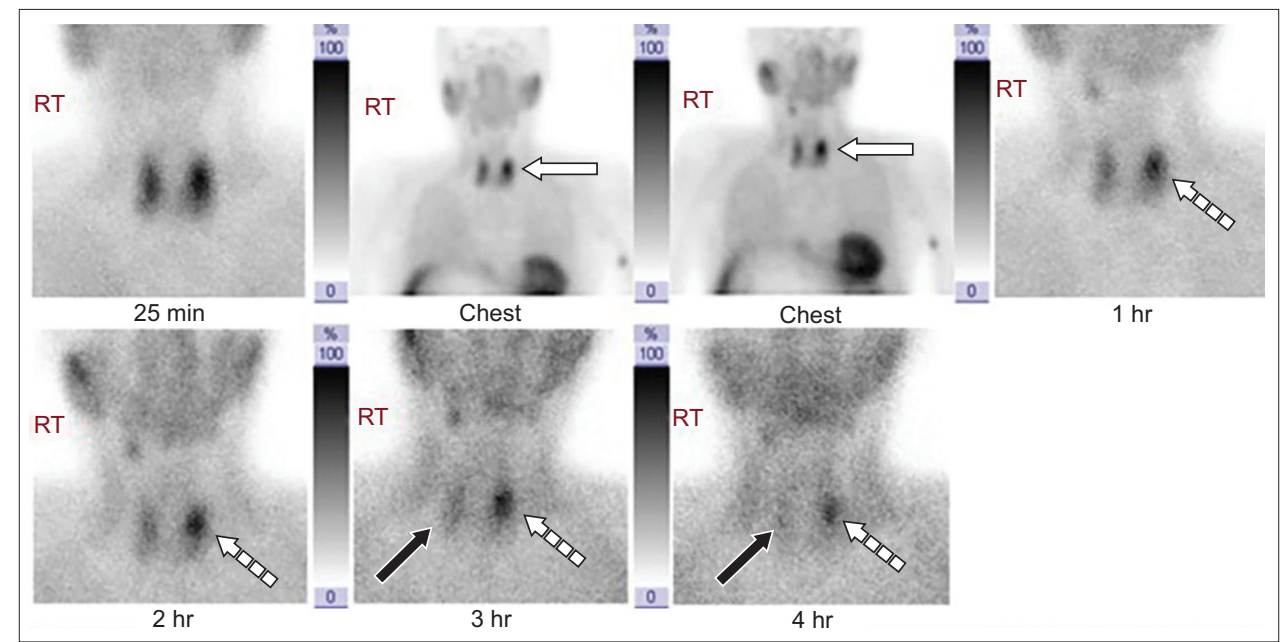

Fig. 1 Tc-99m sestamibi image of the neck.
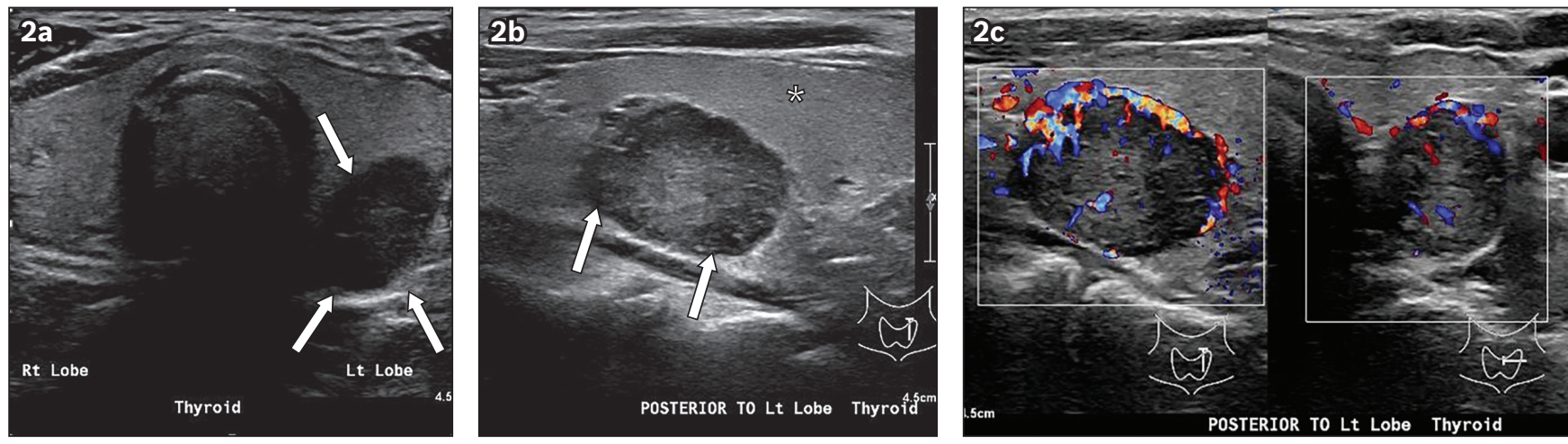

Fig. 2 (a) Transverse and (b) longitudinal US and (c) colour Doppler images.

\section{CASE PRESENTATION}

A 70-year-old man presented to the emergency department with a one-month history of generalised weakness, weight loss and anorexia. There was no pain or localising symptoms. On clinical examination, the patient had normal vital signs and no neck swelling, his lungs were clear, and the abdomen was soft and non-tender. Laboratory tests revealed elevated serum calcium (3.33 mmol/L; normal range [NR] 2.15-2.50 mmol/L).
The patient was admitted for investigation of possible malignancy. Computed tomography (CT) of the thorax, abdomen and pelvis showed no tumour. His parathyroid hormone (PTH) level was very elevated (37.2 pmol/L; NR 1.6-6.9 pmol/L). Nuclear medicine scintigraphy using technetium (TC)-99m sestamibi was performed to obtain planar images (Fig. 1). Neck ultrasonography (US) was also done (Figs. 2a-c). What do the scintigraphy and US images show? What is the diagnosis?

${ }^{1}$ Department of Diagnostic Radiology, Khoo Teck Puat Hospital, Singapore

Correspondence: Dr Syed Zama Ali, Consultant, Department of Diagnostic Radiology, Khoo Teck Puat Hospital, 90 Yishun Central, Singapore 768828. syed.zama@gmail.com 


\section{IMAGE INTERPRETATION}

The Tc-99m sestamibi image (Fig. 1) was acquired following intravenous injection of a radiotracer. Initial dynamic study was done for up to 25 minutes, followed by delayed static images at one hour, two hours, three hours and four hours post injection. A focus of increased tracer localisation (white arrow) and tracer retention in the delayed images (dashed arrow) was noted at the superior pole of the left thyroid lobe, while tracer activity from the thyroid gland appeared washed out (black arrow). Transverse and longitudinal US images of the thyroid (Figs. 2a \& b) showed a solitary hypoechoic nodule (arrows) posterior to the left lobe of the thyroid (asterisk). A colour Doppler image (Fig. 2c) demonstrated moderate peripheral and central vascularity of the nodule.

\section{DIAGNOSIS}

Primary hyperparathyroidism (PHPT) due to parathyroid adenoma.

\section{CLINICAL COURSE}

The patient underwent minimally invasive surgery with excision of a left parathyroid adenoma at the location defined by imaging. An intraoperative frozen section of the specimen confirmed the presence of parathyroid tissue. Intraoperative pre-excision and 15-minute post-excision serum PTH levels were $25 \mathrm{pmol} / \mathrm{L}$ and $6 \mathrm{pmol} / \mathrm{L}$ (NR 1.6-6.9 pmol/L), respectively, indicating a 76\% drop in the PTH level. His serum calcium level also normalised from $2.66 \mathrm{mmol} / \mathrm{L}$ to $2.25 \mathrm{mmol} / \mathrm{L}$ (NR 2.15-2.5 mmol/L). At the four-month clinic follow-up, the patient's biochemistry was in the NR and his clinical symptoms had improved.

\section{DISCUSSION}

The parathyroid glands are responsible for calcium homeostasis. In a classical endocrine negative feedback loop, PTH is released when cell membrane receptors detect low serum calcium. PTH increases serum calcium by stimulating osteoclastic bone resorption and renal hydroxylation of 25-hydroxy vitamin D, which increases gut absorption and reduces renal calcium excretion by increased tubular reabsorption. When serum calcium increases, PTH secretion is switched off.

PHPT is caused by unregulated PTH secretion, which results in hypercalcaemia. The most common cause of PHPT is solitary adenomas (85\%), hyperplasia (15\%) and, rarely, parathyroid carcinoma $(<0.5 \%)$. $^{(1)}$ In the genetically inherited multiple endocrine neoplasia syndromes (Types 1 and 2A), multiple adenomas or hyperplasia of all four glands can occur. ${ }^{(2)}$ Secondary hyperparathyroidism occurs in chronic renal disease with hypocalcaemia and hyperphosphataemia. This results in prolonged stimulation of the glands to secrete PTH. Tertiary hyperparathyroidism occurs when the gland continues to autonomously secrete PTH despite correction of metabolic abnormalities.

PHPT is most common in postmenopausal women. The female-to-male ratio is $3: 1$ and the mean age of patients is 55 years. The reported incidence is one in 500 women and one in 2,000 men per year. ${ }^{(1)}$ The most common presentation is incidental hypercalcaemia on blood panel or mild non-specific symptoms such as malaise or lethargy. The well-known symptoms of hypercalcaemia, remembered by the mnemonic 'painful bones, renal stones, abdominal groans and psychic moans', are uncommon today. Skeletal findings in advanced chronic cases include osteoporosis and fracture, osseofibrous lesions such as Brown tumours, periosteal erosions of the hand phalanges, chondrocalcinosis and pseudogout. Renal tract findings are due to hypercalciuria and stones (Fig. 3). Abdominal findings and symptoms include peptic ulcer, pancreatitis and constipation. Neuropsychiatric symptoms include depression. ${ }^{(3)}$

Diagnosis is confirmed by the presence of hypercalcaemia and an elevated serum PTH above laboratory reference ranges. Other causes of hypercalcaemia can be distinguished by a low serum PTH level, as the gland is functioning normally and hormone release is suppressed. ${ }^{(1)}$

Imaging investigations aim to localise a functioning adenoma. During embryonic development, two pairs of glands develop from the third and fourth pharyngeal pouches. The tissue from the third pouch also differentiates into thymic tissue. Gland location is highly variable. Usually, two glands are located behind the mid thyroid gland and two glands at or just below the thyroid. The glands are ovoid, small, 4-6 mm in size, and may be imbedded in the thyroid gland or separate. However, the glands may be ectopic and migrate into the anterior mediastinum, tracheo-oesophageal groove, paratracheal or paraoesophageal area or carotid sheath. ${ }^{(4)}$

The initial imaging investigation is functional Tc-99m sestamibi imaging; in PHPT, the adenoma appears as a focus of avid persistent uptake greater than that of the thyroid gland. The field of view must include the entire neck and mediastinum to identify ectopic foci. ${ }^{(5)}$ Tc-99m sestamibi imaging can be performed either as dual-phase or subtraction imaging using combined Tc-99m sestamibi and Tc-99m pertechnetate. ${ }^{(6)}$

US imaging is useful for anatomical localisation of an abnormal parathyroid gland, in combination with nuclear medicine. A normal gland is usually not detectable on US imaging. An adenoma is typically enlarged at $10 \mathrm{~mm}$ and hypoechoic relative to the thyroid, and may have variable internal cysts due to necrosis or haemorrhage. Some are hypervascular on colour Doppler US imaging. False negative results may be due to ectopic location or multinodular goitre. ${ }^{(5)}$ Combined US and Tc-99m sestamibi imaging has been reported to achieve $96 \%$ sensitivity and $83 \%$ specificity. ${ }^{(5)}$

For ectopic gland localisation, Tc-99m sestamibi imaging and single-photon emission computed tomography (SPECT)/CT are the primary imaging techniques, supplanted by contrast CT for better anatomical localisation. A combination of Tc-99m sestamibi and SPECT/CT imaging has been reported to achieve $92 \%$ sensitivity. ${ }^{(7)}$ Ectopic parathyroid glands can be seen in the submandibular, intrathyroidal, retro-oesophageal, para-oesophageal and intrathymic locations, as well as along the thyrothymic ligament and in the anterosuperior and posterosuperior mediastinum. In these cases, CT may detect the adenoma as an enhancing nodule and provide the surgeon with a preoperative road map. This is particularly important for lesions close to the carotid sheath, trachea and oesophagus. For example, a Tc-99m sestamibi planar 

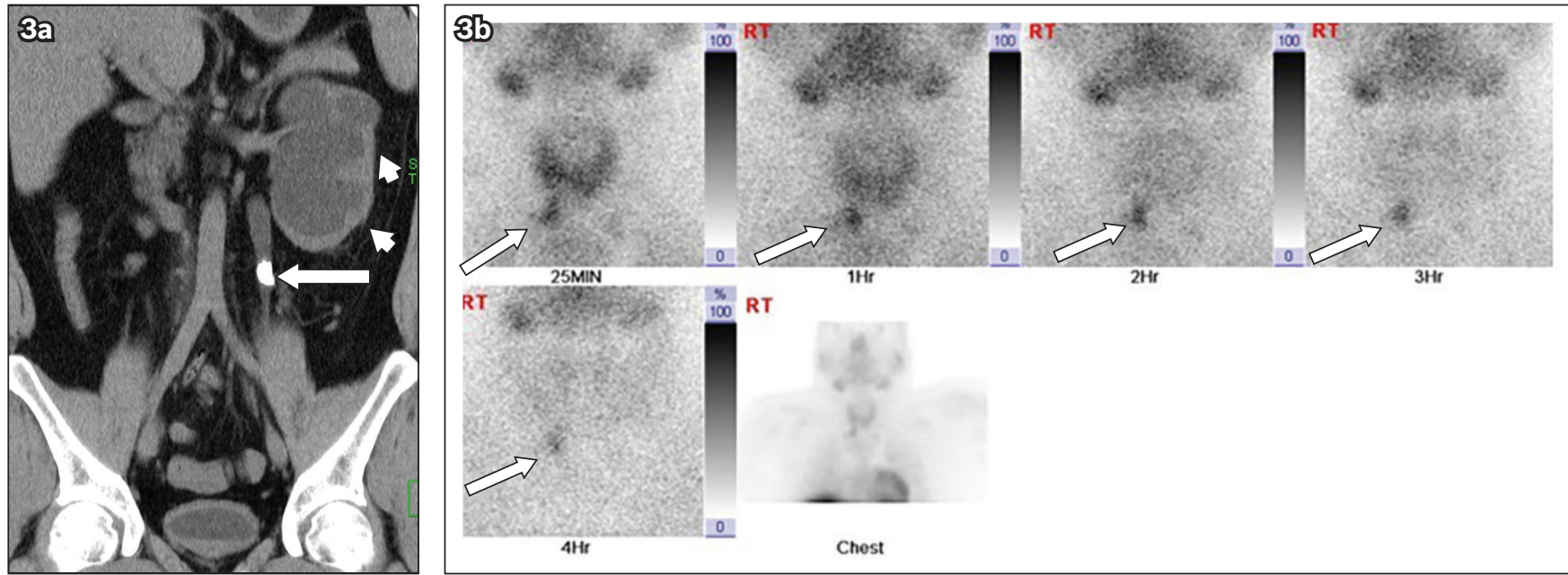

Fig. 3 (a) Coronal non-contrast abdominal CT image of a 27-year-old man shows a left mid ureteric calculus (arrow) that is 10 mm $\times 5$ mm in size with severe hydronephrosis and cortical thinning (arrowheads). Laboratory workup showed elevated serum calcium and serum parathyroid hormone. (b) Tc-99m sestamibi image of the neck shows avid, prolonged tracer uptake below the right lobe of the thyroid (arrows).
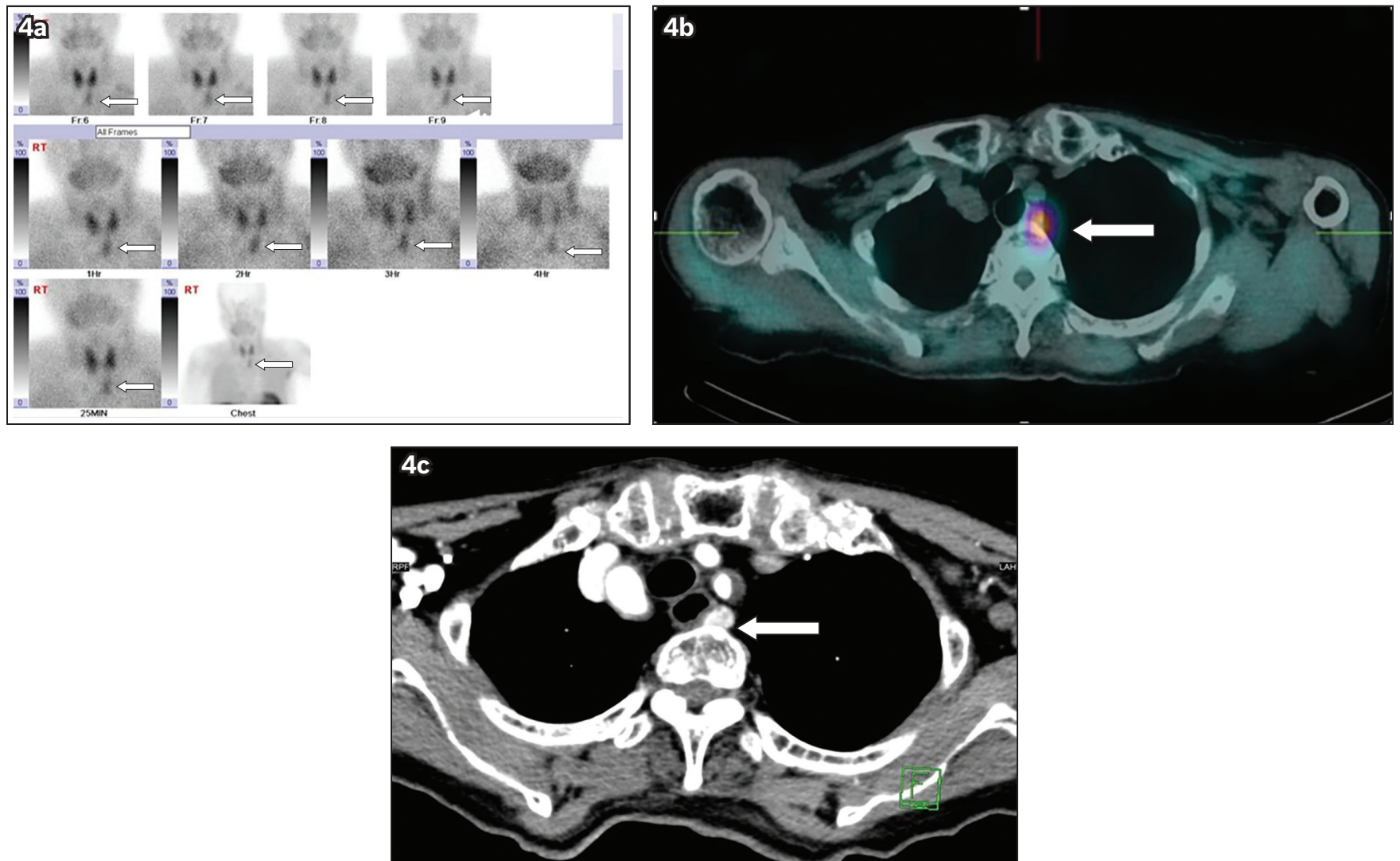

Fig. 4 (a) A Tc-99m sestamibi image of the neck of a 78-year-old woman shows avid, prolonged tracer uptake below the left lobe of the thyroid (arrows). US imaging did not reveal a parathyroid lesion due to the intrathoracic ectopic location. (b) SPECT/CT fusion image shows avid tracer uptake in the posterosuperior mediastinum (arrow). (c) Contrast-enhanced CT image shows an enhancing right paraesophageal nodule compatible with an ectopic parathyroid adenoma (arrow). It also depicts nearby vascular structures, which gives the surgeon a preoperative roadmap.

image of a 78-year-old woman showed tracer uptake below the left thyroid lobe (Fig. 4a), and a fusion SPECT/CT image confirmed the tracer uptake in an ectopic parathyroid gland in the posterior mediastinum (Fig. 4b). Contrast CT image of the neck showed an enhancing nodule in the posterior mediastinum closely abutting the oesophagus (Fig. 4c). Magnetic resonance imaging may also show the lesion but is expensive and has limited availability, and is therefore seldom performed. 18F-fluorocholine positron emission tomography/CT has shown promising results in the detection of parathyroid lesions, especially in re-operative cases, with sensitivity of $96 \%{ }^{(8)}$

Guidelines have been published for the management of PHPT. Surgical excision is the treatment of choice and should be considered in all symptomatic patients. ${ }^{(9)}$ Some authors recommend conservative surveillance if the patient is asymptomatic and has borderline raised calcium and PTH levels. ${ }^{(3)}$ Surgical options include minimally invasive surgery for a localised adenoma. ${ }^{(10)}$ In the operating room, parathyroid tissue can be confirmed by frozen 
section; PTH levels are measured at baseline and 15 minutes after excision to demonstrate a fall in serum PTH levels if the culprit lesion has been removed. In non-localised lesions and hyperplasia, a more challenging bilateral neck exploration and resection of all four glands may be appropriate.

Successful surgery is indicated biochemically by normalisation of serum calcium and PTH levels. Postoperatively, the patient may be temporarily or chronically hypocalcaemic, and is managed with calcium and vitamin D supplements. Clinically, symptoms usually improve or resolve, and bone mineral density increases along with a reduction in fracture risk.

In conclusion, PHPT is usually asymptomatic or has mild nonspecific symptoms, as it is commonly diagnosed early with routine blood tests. Lesion localisation is done using a combination of functional nuclear medicine imaging and anatomic imaging with US. CT can be useful for localising ectopic adenomas and providing a preoperative roadmap. Surgical results are generally excellent, although some advocate conservative management for mild disease with long-term endocrine follow-up.

\section{REFERENCES}

1. Salen PN. Hyperparathyroidism in emergency medicine. Available at: https:// emedicine.medscape.com/article/766906. Accessed May 29, 2020.

2. Scarsbrook AF, Thakker RV, Wass JA, Gleeson FV, Phillips RR. Multiple endocrine neoplasia: spectrum of radiologic appearances and discussion of a multitechnique imaging approach. Radiographics 2006; 26:433-51.

3. McDonald DK, Parman L, Speights VO Jr. Best cases from the AFIP: primary hyperparathyroidism due to parathyroid adenoma. Radiographics 2005; 25:829-34.

4. Peissig K, Condie BG, Manley NR. Embryology of the parathyroid glands. Endocrinol Metab Clin North Am 2018; 47:733-42.

5. De Feo ML, Colagrande S, Biagini $C$, et al. Parathyroid glands: combination of $(99 \mathrm{~m}) \mathrm{Tc}$ MIBI scintography and US for demonstration of parathyroid glands and nodules. Radiology 2000; 214:393-402.

6. Muttarak $M$, Namwongprom S, Sivasomboon C. Clinics in diagnostic imaging (93). Singapore Med J 2004; 45:43-7.

7. Ciappuccini R, Morera J, Pascal P, et al. Dual-phase $99 \mathrm{mTC}$ sestamibi scintigraphy with neck and thorax SPECT/CT in primary hyperparathyroidism: a single-institution experience. Clin Nucl Med 2012; 37:223-8.

8. Amadou C, Bera G, Ezziane M, et al. 18F-fluorocholine PET/CT and parathyroid 4D computed tomography for primary hyperparathyroidism: the challenge of reoperative patients. World J Surg 2019; 43:1232-42.

9. Wilhelm SM, Wang TS, Ruan DT, et al. The American Association of Endocrine Surgeons guidelines for definitive management of primary hyperparathyroidism. JAMA Surg 2016; 151:959-68.

10. van Dalen A, Smit CP, van Vroonhoven TJ, Burger H, de Lange EE. Minimally invasive surgery for solitary parathyroid adenomas in patients with primary hyperparathyroidism: role of US with supplemental CT. Radiology 2001; 220:631-9. 


\section{SINGAPORE MEDICAL COUNCIL CATEGORY 3B CME PROGRAMME} (Code SMJ 202106B)

Question 1. Regarding parathyroid imaging:

(a) Technetium (Tc)-99m sestamibi imaging is useful for localisation of adenomas.

(b) Magnetic resonance imaging is commonly employed for parathyroid imaging.

(c) Parathyroid adenoma does not show contrast enhancement on contrast computed tomography (CT).

(d) Fusion single-photon emission CT/CT is useful in localisation of ectopic parathyroid glands.

Question 2. Regarding primary hyperparathyroidism (PHPT):

(a) The most common cause is parathyroid hyperplasia.

(b) It is associated with multiple endocrine neoplasia (MEN) Type 1 and MEN Type 2A syndromes.

(c) It is most commonly seen in elderly men.

(d) Parathyroid carcinoma is a common cause.

Question 3. Regarding parathyroid gland anatomy and imaging:

(a) Parathyroid glands arise from the third and fourth pharyngeal pouches.

(b) A normal parathyroid gland is typically not seen on ultrasonography.

(c) Tc-99m sestamibi imaging is useful for ectopic parathyroid localisation.

(d) Parathyroid adenomas are usually hyperechoic on ultrasonography.

Question 4. Regarding the clinical and biochemical presentations of PHPT:

(a) It commonly presents with non-specific symptoms such as malaise or lethargy.

(b) It can present with neuropsychiatric manifestations.

(c) Abdominal symptoms include diarrhoea.

(d) A high PTH level will differentiate PHPT from other causes of hypercalcaemia.

Question 5. Regarding the management of PHPT:

(a) An intraoperative fall in PTH level is an indicator of successful surgery.

(b) Bilateral exploration is needed for non-localised lesions.

(c) Patients may need long-term calcium and vitamin D after surgery.

(d) The patient's fracture risk will increase after surgical removal of parathyroid adenomas.

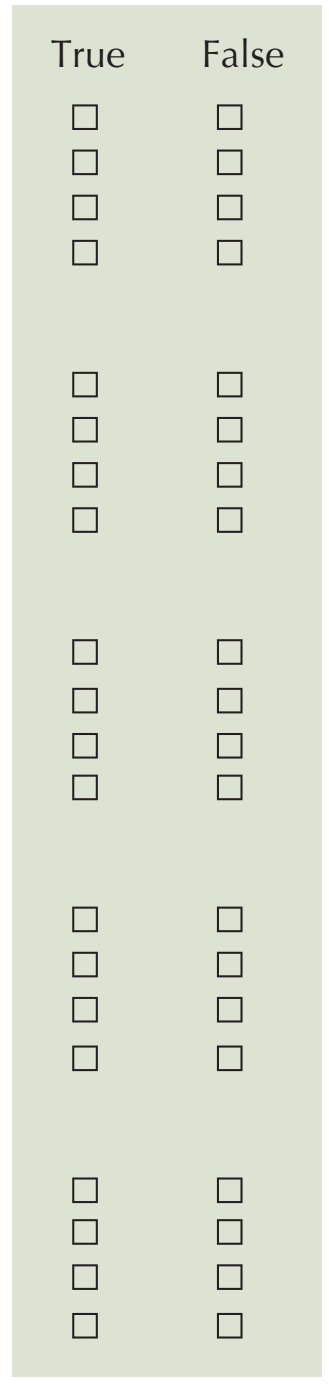

\section{Doctor's particulars:}

Name in full:

MCR no.:

Specialty:

Email:

\section{SUBMISSION INSTRUCTIONS:}

Visit the SMJ website: http://www.smj.org.sg/current-issue and select the appropriate quiz. You will be redirected to the SMA login page.

For SMA member: (1) Log in with your username and password (if you do not know your password, please click on 'Forgot your password?'). (2) Select your answers for each quiz and click 'Submit'.

For non-SMA member: (1) Create an SMJ CME account, or log in with your SMJ CME username and password (for returning users). (2) Make payment of SGD 21.40 (inclusive of $7 \%$ GST) via PayPal to access this month's quizzes. (3) Select your answers for each quiz and click 'Submit'.

RESULTS:

(1) Answers will be published online in the SMJ August 2021 issue. (2) The MCR numbers of successful candidates will be posted online at the SMJ website by 19 August 2021. (3) Passing mark is $60 \%$. No mark will be deducted for incorrect answers. (4) The SMJ editorial office will submit the list of successful candidates to the Singapore Medical Council. (5) One CME point is awarded for successful candidates. (6) SMC credits CME points according to the month of publication of the CME article (i.e. points awarded for a quiz published in the June 2021 issue will be credited for the month of June 2021, even if the deadline is in August 2021).

Deadline for submission (June 2021 SMJ 3B CME programme): 12 noon, 12 August 2021. 